\title{
HABERMAS, PRAGMATISMO E DIREITO
}

\author{
Rachel Herdy* \\ herdy@puc-rio.br
}

RESUMO Jürgen Habermas conta-nos que fora influenciado pelo pragmatismo em três domínios de seu desenvolvimento intelectual: na epistemologia, na teoria social e na teoria política. Neste ensaio, gostaria de acrescentar mais um domínio do desenvolvimento intelectual de Habermas no qual igualmente se poderia supor a influencia do pragmatismo: a filosofia do direito. A exposição será desenvolvida em duas partes. Na primeira, focalizarei especificamente as contribuições epistemológicas de Charles $S$. Peirce, pois é neste autor que Habermas foi buscar a base de sua teoria da racionalidade comunicativa. Na segunda, tecerei algumas considerações sobre as influências de Peirce na teoria discursivo-procedimental do direito de Habermas e apresentarei a proposta de Karl-Otto Apel como contraponto heurístico. O tema a ser explorado é a possibilidade de se enquadrar a filosofia do direito de Habermas na tradição do pragmatismo que descende de Peirce. Certamente, a defesa de uma perspectiva filosófica realista no plano da validade normativa coloca o quadro teórico de ambos em linha de continuidade e, ao mesmo tempo, em contraposição às propostas pragmatistas recentes na epistemologia e no direito.

Palavras-chave Pragmatismo jurídico; Realismo filosófico; Charles $S$. Peirce; Jürgen Habermas; Karl-Otto Apel.

ABSTRACT Jürgen Habermas tells us that he has been influenced by pragmatism in three areas of his intellectual development: epistemology,

* Pesquisadora Visitante (2008-2009), University of Miami School of Law; Doutoranda em Sociologia, IUPERJ; e Professora Licenciada da Pontifícia Universidade Católica do Rio de Janeiro (PUC-Rio). Artigo recebido em jul. 2008 e aprovado em 27 fev. 2009.

KRITERION, Belo Horizonte, no 119, Jun./2009, p. 43-61. 
social theory, and political theory. In this essay I would like to include a further area of Habermas' intellectual development where one could likewise suppose the influence of pragmatism: the philosophy of Law. The presentation will be divided in two sections. First, I will focus specifically on Charles $S$. Peirce's epistemological contributions, as it is in this author that Habermas has searched for the basis of his theory of communicative rationality. Second, I will say something about Peirce's influences on Habermas' discursivetheoretical theory of Law, and present Karl-Otto Apel's proposal as a heuristic counterpoint. The theme here explored is the possibility of framing Habermas philosophy of Law in the pragmatist tradition that descends from Peirce. Certainly, the defense of a realist philosophical perspective in terms of normative validity places their theoretical framework in continuity, while at the same time, in conflict with recent pragmatist proposals in epistemology and the Law.

Keywords Legal Pragmatism; Philosophical Realism; Charles S. Peirce; Jürgen Habermas; Karl-Otto Apel.

Em entrevista a Mithchell Aboulafia (2002), o filósofo alemão Jürgen Habermas conta-nos que a influência do pragmatismo em seu desenvolvimento intelectual se deu em três domínios. Em primeiro lugar, na epistemologia, com Charles Sanders Peirce; em segundo, na teoria social, com George-Herbert Mead; e, em terceiro, na teoria política, com os estudos de John Dewey sobre a "Grande Comunidade". Habermas vislumbra no mais conhecido escrito sobre política de Dewey, O público e seus problemas (1927), uma antecipação dos argumentos expostos em sua tese de doutorado, A transformação estrutural da esfera pública (1962).

Neste ensaio, gostaríamos de acrescentar mais um domínio do desenvolvimento intelectual de Habermas no qual igualmente se poderia supor a influência do pensamento pragmatista: a filosofia do direito. Se grande parte de sua produção intelectual tenha sido animada pelo espírito evolucionista dos pragmatistas clássicos, como Peirce, Mead e Dewey, o que dizer de sua aposta mais recente no campo da filosofia do direito? Não obstante a omissão do autor a esse respeito, poder-se-ia dizer que a filosofia do direito proposta por Habermas no livro Entre fatos e normas: contribuições para uma teoria do discurso do direito e da democracia (1996) — a qual apresenta uma 
compreensão procedimentalista do direito, atribuindo a legitimidade jurídica à existência de condições constitucionalmente asseguradas para a emergência de um "poder comunicativo" - estaria ancorada no conceito de "comunidade de investigadores" de Peirce? $(C P, 5.407) .{ }^{1}$

A questão que se coloca é a seguinte: tendo como referência a tradição filosófica do pragmatismo clássico norte-americano, enquanto importante ponto de inferência do arcabouço teórico habermasiano, qual relação se poderia estabelecer entre os elementos distintivos daquela metodologia e as categorias centrais de sua filosofia do direito? Caso venhamos a dizer que Habermas é sim animado por um espírito pragmatista também no campo do direito, como localizar o seu programa de pesquisa discursivo-procedimental no quadro teórico composto pelos principais projetos do pragmatismo jurídico hoje, como o movimento Law and Economics, capitaneado por Richard Posner (cf. 2007) ou a mais recente démarche do "neoclássico pragmatismo jurídico" de Susan Haack (2006)? E o que dizer, ainda, de sua relação com os pragmatistas jurídicos da antiga tradição clássica, como Oliver Wendell Holmes Jr.? Talvez possamos nos valer aqui de antemão da provocação do velho filósofo pragmatista britânico Ferdinand Canning Scott Schiller (1906): existem, na filosofia, tantos "pragmatismos" quanto há pragmatistas que assim se autointitulam. No mesmo sentido, o historiador americano Arthur O. Lovejoy, em 1908, partindo da controvérsia sobre que tipo de filosofia o pragmatismo implica, na medida em que diversas doutrinas lógicas já haviam sido unificadas sob o mesmo discurso, identifica treze tipos logicamente independentes. "Poderíamos sem inconsistência aceitar qualquer um deles e rejeitar todos os outros" (LOVEJOY, 1963, p. 2). Segundo Lovejoy (1963, p. 29), "o que o movimento assim comumente chamado mais precisa é de uma clarificação de suas fórmulas e a discriminação de certas ideias de pano de fundo importantes e bem fundadas, com relação a certas outras ideias que são bem fundadas, mas não são importantes; e outras que seriam importantes se ao menos não fossem mal fundadas".

Daí explica-se por que, para alguns, a tentativa de enquadrar a filosofia do direito de Habermas na abordagem pragmatista pode parecer estranha, sobretudo quando se tem em mente a posição favorável do filósofo alemão acerca dos universais. A tradição do pragmatismo tem sido frequentemente associada a opções epistemológicas céticas, relativistas, irrealistas e irracionalistas. Nessa esteira, o pragmatismo não demonstraria qualquer preocupação com questões

1 A referência no formato " $C P$, v.p" refere-se aos Collected Papers de Charles Sanders Peirce, seguido pelo volume da obra e, após o ponto, o parágrafo onde se encontra a referência. 
epistêmicas em geral, como o tema da verdade. Contudo, tal estranhamento pode ser afastado quando levamos em conta o fato de que o pragmatismo tem sofrido um processo de "vulgarização" em seu caráter evolucionista, científico e realista. Para Haack (1998, p. 25), o grande responsável por esse "sequestro intelectual" do pragmatismo fora Richard Rorty, com o renascimento da filosofia pragmatista liderada por ele na década de $1970 .^{2}$

A exposição a seguir desenvolve-se em duas partes. Na primeira, considerando-se os três domínios intelectuais em que Habermas confessa ter sido influenciado pelo espírito do pragmatismo, focalizaremos especificamente as contribuições epistemológicas de Charles Sanders Peirce (1839-1914), pois é na semiótica deste autor que Habermas vai buscar a base da sua teoria da racionalidade comunicativa que orienta todas as suas posteriores intervenções. $\mathrm{Na}$ segunda, teceremos algumas considerações sobre as influências do pragmatismo de Peirce em sua teoria discursivo-procedimental do direito. Apresentaremos a proposta pragmatista de Karl-Otto Apel como contraponto heurístico. As contribuições de Habermas e Apel para a filosofia do direito, embora ambas descendam da epistemologia pragmatista de Peirce, divergem no tocante a pontos cruciais. O tema a ser explorado é a possibilidade de se enquadrar a filosofia do direito de Habermas na tradição crítico-realista do pragmatismo que descende de Peirce, em franca oposição às demais abordagens pragmatistas que hoje presenciamos no campo do direito. ${ }^{3}$

A agenda de pesquisa de Peirce abriu um novo horizonte para as investigações epistemológicas de Habermas. Foi o tratamento semióticopragmatista do "significado", inaugurado por Peirce, quando aplicado ao tema epistemológico da "verdade", postulando a intersubjetividade como critério de significação, que permitiu a Habermas propor sua teoria da racionalidade

2 Schiller e James, na verdade, podem ser vislumbrados como os precursores de uma versão antirrealista na história do pragmatismo. Schiller, por todos, pode ser considerado o "precursor primeiro" deste movimento, ao protagonizar uma visão literária da filosofia do pragmatismo sob o nome de "humanismo". Em "The Neglected Argument for the Reality of God" (1908), Peirce conta-nos, em alusão aos trabalhos de Schiller, Studies in Humanism (1907), e James, The Will to Believe (1899): "It seems to me a pity that Mr. Schiller and the pragmatists of today should allow a philosophy so instinct with life to become infected with the seeds of death in such notions as that of the unreality of all ideas of infinity and that of the mutability of truth, and in such confusing notions of thought as that of active willing (willing to control thought, to doubt, and to weigh reasons) with willing not to exert the will (willing to believe)" (CP, 6.485).

3 Para uma melhor compreensão do que vem a ser a abordagem do "realismo-crítico" no pragmatismo de Peirce, cf. APEL, Karl-Otto. Charles Sanders Peirce: from Pragmatism to Pragmaticism. Amherst: Humanity Books, Prometheus Books, 1995. 
comunicativa. O novo horizonte descortinado por Peirce permitiu que Habermas, por um lado, formulasse uma teoria do conhecimento capaz de salvar os insights de Kant sobre a razão humana - embora a tenha colocado definitivamente sob novas bases; por outro, o veio evolucionista de Peirce também franqueou a Habermas conectar a sua teoria crítica da sociedade com o modelo evolucionista de Charles Darwin e, posteriormente, a psicologia do desenvolvimento de Jean Piaget e Lawrence Kohlberg. Tanto Peirce quanto Habermas veem no progresso científico e no desenvolvimento da racionalidade humana um genuíno processo evolutivo de aprendizado da espécie, direcionado sempre para a verdade e o conhecimento real sobre o universo. Peirce oferecia a Habermas, acima de tudo, a possibilidade de um encontro intelectual entre as correntes alemãs e anglo-saxônicas da filosofia moderna.

A partir do século XX, os ataques à filosofia cartesiana centrada na ideia de um sujeito com conhecimento intuitivo passaram a se articular em torno de dois grandes movimentos que têm suas origens no pragmatismo de Peirce - afirma Habermas (1981): o behaviorismo da psicologia social de GeorgeHerbert Mead; e a teoria dos "atos de fala" da filosofia analítica da linguagem de John L. Austin. "Apesar de suas origens comuns no pragmatismo de Charles Sanders Peirce, essas duas abordagens à crítica do conhecimento centrado no sujeito percorreram caminhos separados e tiveram, em suas formas radicais, desenvolvimento independente entre si" (1981, p. 3). Habermas, no curso de seu desenvolvimento intelectual, toma emprestados conceitos centrais (como a noção psicológica de adoção ideal de papéis e a teoria dos atos performativos) desses dois movimentos paralelos que descendem de Peirce para a elaboração de sua ética do discurso [discourse ethics]. Ambos defendem uma epistemologia pragmatista em que o processo cognitivo é assumido como sendo discursivo em todas as etapas. Desse modo, não pode haver conhecimento intuitivo, como prescrevia Descartes; isto é, conhecimento que não tenha sido mediado por um conhecimento prévio. Não há princípios fundamentais ou últimos que possam servir de base para o raciocínio, pois este se dá sempre em cadeia, sendo impossível encontrar o início e o fim de sua linha de continuidade (1968, p. 97).

O primeiro trabalho de Habermas sobre a epistemologia de Peirce fora elaborado em 1963, por ocasião de uma palestra proferida pelo autor em Heidelberg. Logo depois, ao publicar Conhecimento e interesse (1968), Habermas dedica-se a escrever um capítulo sobre Peirce e outro sobre a crítica do pragmatismo à teoria do significado. Na oportunidade, o autor assevera que o primeiro filósofo moderno a postular uma dimensão autorreflexiva para a filosofia da ciência fora Charles Sanders Peirce. Habermas assinala que 
aquilo que distingue Peirce dos demais é o entendimento de que "a missão da metodologia não é clarificar a estrutura lógica de teorias científicas", como pretendia o positivismo lógico, "mas a lógica do procedimento mediante o qual podemos obter teorias científicas" (1968, p. 91). Daí resulta que o sentido da experiência do progresso científico é apropriado por Peirce de maneira inovadora: o pragmatismo peirciano sublinha a estrutura de todo raciocínio que se pretende científico — o seu significado formal (ou procedimental), em oposição às abordagens metodológicas de tipo semântico, focalizadas na dimensão substancial do significado de uma proposição científica qualquer. A partir de Peirce, "nós denominamos que uma informação é científica se e somente se um consenso permanente e não forçado pode ser obtido com relação à sua validade. Este consenso não precisa ser definitivo, mas deve ter o acordo definido como seu objetivo" (1968, p. 91).

Da "arquitetura filosófica" de Peirce, Habermas extrai um conceito-guia fundamental: a ideia de uma "Opinião Final" a ser alcançada por meio de um acordo indefinido e não forçado de uma "comunidade de investigadores" ampliada idealmente no tempo e no espaço. O conceito-guia de "Opinião Final" como resultado de uma investigação ampla da "comunidade de investigadores" encontra-se ligado, por sua vez, aos conceitos de "realidade" e "verdade" para Peirce:

O real, portanto, é aquilo em que, mais cedo ou mais tarde, a informação e a racionalidade acabarão definitivamente resultando, e que, portanto, é independente da minha e da sua vontade. Portanto, a origem mesma do conceito de realidade mostra que este conceito implica essencialmente a noção de uma comunidade sem limites definidos e capaz de um indefinido aumento do conhecimento $(C P, 5.311)$.

Dentro do paradigma epistemológico que emerge do giro pragmatistasemiótico, os temas da "verdade" e da "realidade" de um signo qualquer passam a não depender de sua correspondência direta a um objeto externo, mas de sua correspondência ou referência a um signo como objeto externo mediante razões internas que possam ser aceitas por uma comunidade de investigadores. Surge, assim, a categoria do "interpretante" enquanto elemento central na semiótica peirciana: "Uma coisa não pode estar para algo sem estar para algo por algo" (HABERMAS, 1989, p. 39). Enquanto no antigo quadro teórico da filosofia da consciência o conhecimento baseava-se numa relação direta entre sujeito e objeto - uma relação de tipo diádica, cujo resultado seria mera "cópia" da realidade - a filosofia semiótica de Peirce fundamenta-se numa relação triádica entre "sujeito", "objeto" e "interpretante". Assim é que o critério para se determinar o conhecimento deixa de ser a certeza privada de um sujeito 
no curso de suas investigações e passa a localizar-se nas práticas públicas de justificação perante uma "comunidade de investigadores". Habermas afirma: "a 'verdade' se torna um conceito de validade triplamente localizado. A validade de proposições que são, em princípio, falíveis é mostrada como sendo uma validade que é justificada para um público" (2000, p. 39). O lugar da subjetividade na epistemologia cartesiana passa a ser ocupado pelo "espaço público" da intersubjetividade na epistemologia peirciana; o conhecimento passa a ser determinado pela comunicação mediada por argumentos capazes de conseguir o assentimento de todos os participantes: o "eu cogito" é substituído pelo "eu argumento".

Toda a discussão epistemológica de Peirce acerca da "Opinião Final" só pode ser entendida tendo como pano de fundo a complexa arquitetônica filosófica do autor. Com efeito, a noção de uma "Opinião Final" que se identificaria com a "verdade" e a "realidade" encaixa-se no projeto maior de uma "metafísica científica" e "reformada", fundamentada em uma ordem cosmológica evolucionista. Neste projeto, Peirce destaca o princípio do "agapismo", ou a doutrina do "amor evolucionário", em oposição ao princípio do "tiquismo", que representa a doutrina, por ele também aceita, de que a chance absoluta é um fator presente no universo. $\mathrm{O}$ autor defende a ocorrência de uma evolução desde o caos inicial para uma ordem final pautada pelo princípio do "amor criativo". O mecanismo central que direciona o "agapismo" é, por sua vez, o famoso princípio do "sinequismo" — ou a "Lei da Mente", mobilizada por Peirce pela primeira vez no artigo "The Law of Mind" (1892). Com a defesa do princípio do "sinequismo", o autor sugere que há uma continuidade entre os conceitos intelectuais no mundo. $\mathrm{O}$ "sinequismo" é visto como um princípio lógico diretivo do raciocínio, o qual descreve o tipo de hipótese que se poderia investigar e sobre a qual se poderia discorrer com sucesso. $\mathrm{O}$ "sinequismo" estabelece a preferência lógica por hipóteses que sugerem a existência de continuidades em vez de rupturas ou disjunções entre significados. A ideia, segundo Haack (2006b, p. 142), significa que "devemos procurar continuidades subjacentes, e reconhecer que distinções supostamente rígidas podem ser mais bem concebidas como linhas de demarcação desenhadas em algum ponto do continuum".

A hipótese agapista e sinequista é apresentada por Peirce como aplicável tanto à evolução da "Mente" (enquanto logos do universo) como ao movimento das "mentes" humanas (enquanto cérebro que busca entender os objetos no mundo). Sugere-se uma harmonização entre as "mentes" humanas, com toda a sua plasticidade e adaptabilidade, e a "Mente" do universo, em toda a sua perfeição. Abstraindo-se das indagações típicas da filosofia da mente norte- 
americana - cujas investigações são, no mínimo, intrigantes —, é curioso sublinhar aqui que a autoridade epistêmica da filosofia do pragmatismo, capaz de nos dizer como se constituem a verdade e a realidade, provém da "Opinião Final" das mentes humanas treinadas em sua investigação indefinida na comunidade. Ora, além de ser realista, no sentido de que há entidades gerais e universais independentes do que possam conceber as mentes humanas, a filosofia de Peirce é também idealista, pois consagra a existência de uma realidade objetiva que é, ao mesmo tempo, configurada na "comunidade de investigadores". A conjugação de "realismo" e "idealismo", normalmente contrapostos em filosofia, torna-se possível em virtude do princípio do "sinequismo": os conceitos são internos à idealização das mentes, mas também são contínuos com os demais princípios da realidade (se é que esses princípios são reais de alguma maneira).

É oportuno destacar aqui a ideia de "realismo inocente", defendida por Haack em Reflexions on Relativism (1998, p. 156). Apropriando-se da ideia de "realismo" de Peirce - o qual, por sua vez, valeu-se dos ensinamentos de John Duns Scotus - Haack pretende, mediante a defesa de um "realismo inocente", construir a ideia de real em contraste com a ideia de que o mundo possa vir a ser uma ficção, pois a verdade não é somente uma questão de convenção científica; há também um elemento de base objetiva. O grande problema consiste na possibilidade de se articular o "realismo inocente" sem ter de endossar um realismo metafísico de tipo platônico; sem apelarmos a uma totalidade fixa de objetos independentes da mente, afirma Haack (1998, p. 157). Como articular esta forma de realismo de modo a dar conta também do pluralismo conceitual e da mudança conceitual?

Haack destaca uma diferença entre o que é externo e o que é interno na categoria do "real". No primeiro caso, trata-se de algo que é independente não somente do que qualquer pessoa possa vir a pensar, como também do que nós possamos vir a pensar no curso de nossas investigações falíveis; já na segunda hipótese, trata-se de algo que é independente do que qualquer pessoa possa vir a pensar, mas não do que nós pensamos. Assim, o termo "independente da mente" possui uma interpretação forte (independente do que nós podemos vir a pensar) e uma interpretação fraca (dependente do que pensamos) — os elementos externos e internos do real, respectivamente. Essa distinção ganha destaque quando apreciamos a categoria da "verdade" como fonte da Opinião Final em Peirce. "Pois a concepção de Peirce sobre a realidade possui dois aspectos (...). A verdade, ele sustenta, embora independa do que eu ou você ou qualquer outra pessoa pense que ela seja, é aquilo que está representado na opinião final" (HAACK, 1998, p. 163). Ora, a verdade, embora tenha um 
caráter real externo, porque independente do que eu ou você ou qualquer pessoa venha a pensar no curso da investigação humana, depende também do pensamento humano.

Daí decorre que, embora o autor defenda uma epistemologia por meio da qual o conhecimento esteja situado na comunidade e visto como um processo idealmente ampliado no tempo e no espaço, a "verdade" e a "realidade" não têm nada a ver com standards culturais ou convenções comunitárias instransponíveis. Para Peirce, "o pensamento, controlado por uma lógica racional experimental, tende à fixação de certas opiniões, igualmente destinadas, cuja natureza será a mesma no final, embora a perversidade do pensamento de toda uma geração possa causar a prorrogação da fixação última" $(C P, 5.430)$. Neste ponto, Habermas é incisivo: "A compreensão contextualista da virada lingüística, da qual esse anti-realismo emerge [aqui o autor tem como mirada o neopragmatismo de Rorty], remete a uma concepção anterior, da ascensão e queda dos paradigmas, que exclui a continuidade de temas entre paradigmas, bem como de processos de aprendizagem que se estendem de um paradigma a outros" (HABERMAS, 2000, p. 38).

A questão que se coloca é a seguinte: se a "realidade" e a "verdade", para Peirce — da mesma forma que a "justificação", para Habermas devem ser definidas pela totalidade das crenças aceitas pela "comunidade de investigadores" idealmente ampliada no tempo e no espaço, por que não podemos dizer que a própria estrutura da realidade que os autores afirmam existir não é (ela mesma) elucidada em termos de linguagem? Peirce e Habermas continuam a enfrentar velhas questões epistemológicas: como é possível a objetividade do conhecimento se temos de nos conformar ao círculo de discursos e práticas (cf. APEL, 1973)? Como sair da linguagem usando a linguagem? Como fazer valer a ideia de uma realidade independente de nós, se a "verdade" é sempre determinada, em última instância, pela "Opinião Final" de uma comunidade? Será que não estaríamos simplesmente recolocando, agora sob nova roupagem, o problema epistêmico clássico que marca a velha tradição da metafísica cuja filosofia transcendental Peirce e Habermas buscaram superar?

No trecho que expomos a seguir, Habermas expressa a sua visão da transcendentalidade que emerge "a partir de dentro" da comunidade:

Como não podemos sair da esfera da linguagem e da argumentação, a referência à realidade (...) só pode se estabelecer se projetarmos uma "transcendência a partir de dentro". Para isso serve o conceito contrafático de Opinião Final ou de um consenso alcançado em condições ideais. A aceitabilidade racional, e com ela a verdade de uma afirmação, Peirce faz depender de um acordo que se pudesse alcançar sob condições de comunicação de uma comunidade de investigadores idealmente ampliada no 
espaço social e no tempo histórico. Se entendermos a realidade como a soma de todas as afirmações verdadeiras neste sentido, pode-se ter em conta sua transcendência sem necessidade de abandonar a conexão entre objetividade do conhecimento e intersubjetividade do entendimento. (HABERMAS, 1989, p. 51)

De modo semelhante, Peirce defende o seu argumento a favor da objetividade do real por meio da ideia de "idealismo condicional", afirmando que a verdade consiste no fato de que todo investigador sincero será levado a abraçá-la — "e se ele não for sincero, os efeitos irresistíveis da investigação à luz da experiência o farão ser". "Esta doutrina parece ser para mim", afirma Peirce, "um corolário do pragmatismo. Eu chamo essa forma de 'idealismo condicional"" (CP, 5.494). A "realidade" e a "verdade", embora essas duas ideias existam somente ao redor da "Opinião Final" de uma "comunidade de investigadores" que sobre tais assuntos resolveu concordar em determinado tempo e lugar, não podem ser arbitrárias. Certamente, "todo pensamento humano e opinião contêm um elemento arbitrário, acidental, dependente das limitações das circunstâncias, do poder, e da inclinação do indivíduo; um elemento de erro, em suma" (PEIRCE apud HABERMAS, 1968, p. 93). "Mas a opinião humana tende universalmente no longo caminho a uma forma definida, que é a verdade" (Ibidem), porque a "realidade" e a "verdade" representam aquele consenso que será sempre mantido em condições favoráveis pela "comunidade de investigadores" até a consagração da "Opinião Final”. Nas palavras de Peirce:

Deixe qualquer ser humano ter informações suficientes e exercer pensamento suficiente sobre qualquer questão, e o resultado será que ele chegará a certa conclusão definida, a qual é a mesma que qualquer outra mente chegará sob condições suficientemente favoráveis... Existe... para cada questão, uma resposta verdadeira, uma conclusão final, em relação à qual a opinião de todo homem está constantemente gravitando. (Apud HABERMAS, 1968, p. 93).

$\mathrm{Na}$ esteira do pragmatismo de inspiração crítico-realista de Peirce, Habermas afirma que "a virada pragmática não deixa espaço para dúvidas quanto à existência de um mundo independente de nossas descrições”. Muito pelo contrário, diz ele, "desde Peirce a Wittgenstein, a ociosa dúvida cartesiana foi rejeitada como uma contradição performativa — 'se você tentasse duvidar de tudo, você não chegaria a duvidar de nada'. O jogo de duvidar em si pressupõe a certeza" (2000, p. 39).

Do quadro exposto nesta primeira parte do trabalho, identifica-se a existência de uma tensão no interior da própria epistemologia de Peirce. Afinal, como pretender atribuir autoridade epistêmica à opinião de uma comunidade 
de homens investigadores? A seguir, pretendemos abordar de que maneira essa tensão se materializa na filosofia do direito de Habermas. A tentativa deste autor de construir uma sociologia do direito situada na "eticidade" do mundo da vida conflita com a sua proposta no campo da filosofia do direito de buscar enfrentar o desafio universalista e realista no campo das normas jurídicas. ${ }^{4}$ Quando Habermas incorpora a autoridade epistêmica da "comunidade de investigação" no direito, realiza uma transposição, para o sistema jurídico, da tensão entre fatos e valores inerente à epistemologia do pragmatismo críticorealista de Peirce. Interessa-nos analisar o modo como Habermas solucionará esta tensão, quando analisado comparativamente com a orientação de KarlOtto Apel.

\section{2}

Em Entre fatos e normas: contribuições para uma teoria do discurso do direito e da democracia (1996), Habermas apresenta, pela primeira vez, a sua filosofia do direito. Nesta obra, o autor retoma a sua teoria da ação comunicativa como particularmente apropriada para enfrentar a tensão que, segundo ele, tem marcado historicamente todas as teorias modernas no campo da filosofia do direito. A tensão reside na relação aparentemente contraditória entre a "faticidade" de um sistema jurídico cuja existência deve ser encarada de modo empírico-sociológico e a "validade" abstrata das pretensões normativas sustentadas no direito positivo. Na medida em que a autoridade epistêmica de uma "Opinião Final" da comunidade é assumida como um conceito-guia contrafático por Habermas para se determinar também a autoridade epistêmica no campo do direito (e da política), quer dizer, como critério de validade das normas de um Estado democrático de direito, a filosofia do direito habermasiana incorpora no seu âmago a tensão identificada na epistemologia pragmatista de Peirce. Podemos recuperar, portanto, na própria epistemologia pragmatista de Peirce, a tensão entre fatos e normas, o mote da obra monumental de Habermas no campo da filosofia do direito.

Segundo Habermas, em face da virada pragmático-linguística, a busca pela legitimidade do direito já não pode mais recorrer às teorias do direito

4 Para evitar confusões terminológicas, é preciso ressaltar os diferentes significados que o emprego do termo "realismo" produz na filosofia e no direito. Ser realista, no campo da filosofia, significa acreditar na existência de uma realidade objetiva e externa à vontade do homem; no direito, fala-se em realismo para sublinhar a ausência de valores ou princípios externos à vontade do magistrado. Enquanto o direito, na perspectiva realista, depende do que pensa o juiz; o mundo, na filosofia realista, independe do que pensa o homem ou a comunidade. Aqui, adota-se o termo em sua acepção filosófica. 
natural ou às propostas positivistas que prescrevem a gênese sociológica do direito. Com efeito, o que se impõe é uma teoria discursiva do direito e da democracia. Esta teoria contém uma tensão conceitual que lhe é implícita: como explicar o fato de que uma "comunidade de investigadores" (Peirce) ou uma "comunidade da comunicação" (Apel) ou — o que é o mesmo — os participantes de um discurso conformado por uma "situação ideal de fala" (Habermas) possam, não obstante a sua inserção fática em um contexto histórico-cultural determinado, pretender alcançar a verdade última de uma "Opinião Final" no que diz respeito às normas universalmente válidas no direito - a "normatividade"?

Mais propriamente, não se trata de uma tensão localizada em algum ponto específico da filosofia do direito de Habermas, mas que se manifesta em diversos níveis de sua análise - como nas relações de tensão entre autonomia pública e autonomia privada; soberania popular e direitos humanos; legalidade e legitimidade; entre outras. Habermas objetiva dar conta de todas essas tensões por meio de uma proposta que, paradoxalmente, estabelece a ideia de "cooriginalidade" (ou de "equiprimordialidade") entre os pontos que supostamente se encontravam em oposição. A "cooriginalidade" entre os pontos dantes em tensão decorre do fato de que um é condição de possibilidade para a existência do outro. Não temos o objetivo de entrar nos pormenores deste tópico. É suficiente salientar que a perspectiva conciliadora de Habermas evita uma recaída nas clivagens que têm tradicionalmente marcado a teoria política moderna. Entre teorias "comunitárias", que privilegiam a importância da autonomia pública e da soberania popular, e teorias "liberais", que sublinham a superioridade da autonomia privada, o autor posiciona-se no meio deste conflito, reconciliando a tensão entre liberais e republicanos ao propor um horizonte político-jurídico baseado na estrutura da comunicação determinada de modo formal-pragmático (e, de acordo com ele, neutro) em função de uma "ética do discurso".

Assim é que a solução de Habermas para todas essas tensões assinaladas encontra-se na análise dos pressupostos que sempre e desde já [always already] mostram-se necessários para a prática da ação comunicativamente orientada. Tais pressupostos foram formulados inicialmente pelo programa de pesquisa conduzido por Apel e Habermas, intitulado "Pragmática Universal". $\mathrm{Na}$ década de 1970, os dois autores assumiram em conjunto a tarefa de construção da chamada "ética do discurso" [discourse ethics], cujo programa de pesquisa fora denominado "Pragmática Universal". Este programa de pesquisa tinha como objetivo "identificar e reconstruir as condições universais de possibilidade do entendimento mútuo" (HABERMAS, 1976, p. 21) entre 
os participantes do discurso na "comunidade de investigadores" concebida por Peirce. Os autores buscavam explicar o ponto de vista a partir do qual normas de ação em geral poderiam ser justificadas perante uma comunidade universal. Apel e Habermas concluem que o critério de justificação encontrarse-ia nos pressupostos comunicativos capazes de encetar a busca pelo acordo. Para alcançarmos este acordo, é preciso que sejamos capazes de imaginar contrafaticamente aqueles pressupostos discursivos procedimentais implicados no processo argumentativo (como as noções de verdade, correção normativa, autenticidade e sinceridade). Quando os indivíduos resolvem dar início a uma discussão e performar posições ideais de falante e ouvinte no discurso prático, há um comprometimento ético-procedimental recíproco que constitui as pressuposições necessárias de toda ação comunicativa. Assim, a proposta de uma "ética do discurso" encontra seu fundamento numa determinada forma que representa a estrutura de qualquer processo de argumentação. No livro Entre fatos e normas, Habermas faz uma recapitulação de sua teoria do discurso mediante a análise da teoria da argumentação, atribuindo centralidade ao papel do direito como médium privilegiado para a institucionalização, por meio de um "sistema de direitos", das condições gerais necessárias à emergência do acordo e da própria legitimidade do direito. O movimento do constitucionalismo na teoria do Estado permitiu a institucionalização, no médium do direito, dos procedimentos formais para o exercício da argumentação na comunidade.

Contudo, embora ambos compartilhem do mesmo interesse, marcado pela construção de uma filosofia crítica da sociedade, diferenças importantes no que diz respeito às estratégias conceituais empreendidas por esses dois autores resultaram em duas proposições teóricas distintas, as quais refletem, hoje, duas concepções diferentes no quadro da filosofia do direito que descende do pragmatismo de Peirce. Segundo Apel, o ponto de divergência entre ele e Habermas decorre de uma suposta incoerência e inconsistência na reformulação do projeto levada a cabo por este último. Antes do rompimento com Apel, Habermas entendia que, "se os limites da semiótica significam os limites do mundo, então o sistema de signos e a comunicação entre os usuários de signos passam a ocupar, por assim dizer, uma posição transcendental” (1989, p. 54). A partir da publicação de sua obra dedicada à filosofia do direito, Habermas pretende sustentar a possibilidade de universalização de pleitos normativos (como aqueles relativos à internacionalização dos direitos humanos), sem assumir, como contrapartida necessária, a ideia pressuposta nessa sua pretensão universalista de que o direito per se depende normativamente de um argumento de natureza moral. Apel acredita que, para se proceder à identificação das condições universais de possibilidade do entendimento mútuo, é preciso 
buscar aqueles constrangimentos "transcendentais" (porque normativamente necessários) que sempre e desde já pressupomos com relação a nós mesmos e aos demais participantes. Ao negar o estado "transcendente" desses pressupostos, Habermas cometeria uma petitio principii, afirma Apel. Melhor dizendo, Habermas cometeria uma "contradição performativa". Valendo-se da teoria dos atos performativos, Apel é levado a afirmar que as pressuposições necessárias para que não entremos em "contradição performativa" no discurso transcendem o mundo empírico da comunicação, impondo-se externamente, de maneira absolutamente necessária, sobre a comunidade que queira se orientar comunicativamente. Ao longo do tempo, as pressuposições nunca mudaram, nunca mudam e nunca mudarão. E é por isso que não podemos vê-las a partir de uma perspectiva histórico-sociológica, como decorrentes da "eticidade" do mundo da vida, como quer Habermas.

Foi a tematização do problema transcendental a partir de Peirce o ponto de desengate entre Habermas e Apel. Enquanto Apel insiste na ideia de uma filosofia pós-metafísica, que é, todavia, "transcendental”, Habermas tem como objetivo salvar uma noção compreensiva da racionalidade humana sem ter de recorrer ao que "transcende" o mundo empírico de nossos contextos sociais, pois isso significaria um retorno à velha tradição do direito natural. As pretensões de validade necessariamente presentes na prática comunicativa encontram-se situadas em contextos sociológicos do mundo empírico. Apel deu um passo a mais ao introduzir o tema "prope-metafísico" da filosofia transcendental no projeto da "Pragmática Universal" que ambos construíram em conjunto. Explicam-se, dessa forma, as terminologias distintas que passaram a ser adotadas pelos dois autores: Habermas prefere falar em "Pragmática Formal", ao passo que Apel faz referência à "Pragmática Transcendental". 5

A transcendência é projetada por Apel a partir da comunidade de investigação; trata-se de uma transcendência que, quando bem compreendida, parte do interior do próprio processo discursivo. Assim é que a "comunidade da comunicação", para Apel, pode ser pensada como sendo a priori. Habermas adentra o campo "prope-metafísico" com mais cautela: a comunidade de

5 Apel levou a cabo três tentativas de orientação "transcendental-pragmática" para se pensar "com Habermas, contra Habermas". A primeira, em 1989, intitulou-se "Fundamentação normativa da teoria crítica: recorrendo à eticidade do mundo da vida?"; a segunda, em 1994, foi realizada sob o título "O problema do emprego lingüístico francamente estratégico na perspectiva transcendental-pragmática"; e, finalmente, a terceira, publicada em 1998, chamou-se "Dissolução da ética do discurso? Quanto à arquitetônica da diferenciação discursiva em Faticidade e validade de Habermas". Neste último trabalho, Apel afirma tratar-se de uma reabilitação do programa da "ética do discurso", supostamente abandonado por Habermas ao estabelecer uma distinção entre os discursos da razão prática em sua obra Entre fatos e normas: contribuições para uma teoria do discurso do direito e da democracia (1996). 
investigadores é, para ele, quasi-transcendental. "Quasi” porque, não obstante a sua condição necessária e pressuposta, a comunidade precisa concretizar-se sob condições que são empíricas, estando sempre situada em contextos espaciais e históricos. A recusa de Habermas em transcendentalizar a filosofia está marcada, também, pela defesa de um pensamento que se diz "pós-metafísico" - embora a sua pós-metafísica nada tenha de "antimetafísica"; constitui, arrisca-se dizer, uma forma de pensamento em muitos aspectos parecida com a proposta de Peirce de uma "metafísica científica" ou "reformada".

A crítica de Apel refere-se à diferenciação que Habermas pretende estabelecer, notadamente no terceiro capítulo de Entre fatos e normas, entre o "princípio da moral" e o "princípio do direito". Habermas quer evitar uma subordinação do direito positivo a uma norma de direito natural ou à moralidade. O autor supõe que, "no nível pós-metafísico de justificação, regras jurídicas e morais diferenciam-se simultaneamente da vida ética tradicional e aparecem lado a lado como dois tipos de norma de ação diferentes, mas mutuamente complementares" (1996, p. 105). A racionalidade prática que Habermas pretende recuperar a todo custo assumiria significados diferentes de acordo com a norma de ação a demandar justificação. Em se tratando de justificar uma norma de ação pertencente ao campo da moral, aplicar-se-ia o "princípio da moral" - na forma de um "princípio de universalização (U)"; em contrapartida, em se tratando de uma norma de ação pertencente ao campo do direito, aplicar-se-ia o "princípio do direito" — na forma de um "princípio da democracia". Embora ambos os princípios possam ser reconduzidos à máxima inscrita no "princípio do discurso", formulado de maneira formalpragmática, refletindo "aquelas relações simétricas de reconhecimento construídas a partir de formas de vida estruturadas comunicativamente" (1996, p. 109), expressando exigências pós-convencionais de justificação, os campos da moral e do direito não podem ser equiparados, embora possam ser, de fato, complementares. "Apesar de seu conteúdo normativo, ele [o princípio do discurso] reside em um nível que é ainda neutro com relação à moralidade e ao direito, pois se refere a normas de ação em geral (HABERMAS, 1996, p. 107). Significa dizer: "o direito não imita a moral":

Essa construção é guiada pela intuição platônica de que a ordem jurídica imita a ordem noumênica de um "reino de fins" e, ao mesmo tempo, a corporifica no mundo fenomênico. Mais especificamente, o legado platônico ainda vive na duplicação do direito em direito positivo e direito natural. Com isso, quero dizer a intuição de que uma comunidade ideal de sujeitos morais responsáveis — a comunidade da comunicação ilimitada de C. S. Peirce a Josiah Royce a Karl-Otto Apel - entra pelo médium do direito na arena do tempo histórico e do espaço social e adquire a forma concreta, situada temporal e espacialmente, de uma comunidade legal. Essa intuição 
não é inteiramente falsa, pois uma ordem legal só pode ser legítima quando não contradiz princípios morais básicos. Em virtude dos componentes de legitimidade da validade jurídica, o direito positivo tem uma referência à moralidade que está inscrita nele. Mas essa referência moral não pode nos conduzir a posicionar a moralidade acima do direito, como se houvesse uma hierarquia de normas. (HABERMAS, 2006, p. 106)

Habermas prefere recorrer à ideia de "eticidade" do mundo da vida para determinar o "princípio do discurso" e a própria co-originalidade entre direito e moral, ao passo que Apel supõe a necessidade de uma fundação tomada a priori (1998, p. 75). Para Habermas, a duplicação na concepção do direito em, de um lado, o direito moralmente válido e, de outro, o direito moralmente inválido é não só implausível em termos sociológicos como acarreta consequências normativas aberrantes. Do ponto de vista sociológico, embora a moral e o direito tenham nascido simultaneamente — de forma co-originária, portanto com o rompimento da visão platônica do mundo ocorreu um processo de diferenciação entre questões jurídicas e questões morais. Hoje, ainda que o direito e a moral façam igualmente referência ao problema da conduta, referem-se ao tema de forma diferente.

Gostaria de encerrar este ensaio sobre a possibilidade de "rotularmos" a filosofia do direito de Habermas no quadro referencial do pragmatismo peirciano recorrendo a algumas considerações acerca de uma pretensa relação de semelhança que podemos entrever entre o "princípio do discurso" e a "Máxima Pragmática" de Peirce. Sabemos, de antemão, que esses dois postulados formularam-se tendo em vista propósitos diferentes: o primeiro tem como objetivo explicar o ponto de vista a partir do qual "normas de ação" podem ser justificadas; o segundo pretendia estipular a maneira correta para se determinar o verdadeiro significado de um conceito, que se manifesta concebivelmente na conduta humana. ${ }^{6}$ Em última instância, contudo, ambos os postulados referem-se, sob diferentes roupagens, a certa forma de raciocínio capaz de determinar a "correção" de uma norma de ação.

6 Vale notar que não se trata das implicações do significado sobre a conduta concreta, mas sobre como podemos conceber tais implicações para a nossa conduta em um mundo possível — o significado não pertence à categoria da Segundidade de Peirce, àquilo que está aqui e agora (hic et nunc), mas à categoria da Terceiridade, àquilo que está destinado a ser no curso final da investigação. Ao salientar o caráter não atualizado, não concreto, da Máxima Pragmática, Peirce passou a considerar (embora tardiamente) a centralidade das ciências normativas (lógica, ética e estética) em relação à sua filosofia. Peirce escreveu: "The importance of the matter for pragmatism is obvious. For if the meaning of a symbol consists in how it might cause us to act, it is plain that this 'how' cannot refer to the description of mechanical motions that it might cause, but must intend to refer to a description of the action as having this or that aim. In order to understand pragmatism, therefore, well enough to subject it to intelligent criticism, it is incumbent upon us to inquire what an ultimate aim, capable of being pursued in an indefinitely prolonged course of action, can be" (CP 5.135, 1903). 
O “princípio do discurso (D)" impõe a sua lógica ao precisar que "somente são válidas aquelas normas de ação com as quais todas as pessoas possivelmente afetadas poderiam concordar como participantes em discursos racionais". E mais, é preciso que todos os participantes e possíveis afetados possam aceitar as consequências e os efeitos colaterais que resultariam da observação geral da norma para a satisfação do interesse de todos; e que essas consequências e efeitos colaterais resultantes da observância geral da norma sejam preferidos às demais possibilidades alternativas conhecidas para a regulação daquela conduta. Podemos inferir uma semelhança entre o "princípio do discurso" de Habermas e a "Máxima Pragmática" de Peirce. Recordemos esta última: "Considere quais efeitos, que possam concebivelmente ter implicações práticas, nós concebemos ter o objeto de nossa concepção. Então, nossa concepção sobre tais efeitos é o todo da nossa concepção sobre o objeto" ( $C P$, 5.402). Ambos depositam a força da validade (de uma norma de ação, no caso de Habermas; e do significado de um conceito, que se traduz em uma norma de ação concebida, no caso de Peirce) nas consequências. Em Habermas, são aquelas consequências que podem ser "antecipadas"; em Peirce, são os efeitos que podem ser "concebidos".

Acredito que a filosofia do direito de Habermas sustenta-se na intuição metodológica de Peirce, a qual ganha expressão pragmática no "princípio do discurso", orientador do "princípio do direito" e do "princípio da moral". A própria concepção filosófica do direito de Habermas parece ser, ela mesma, pragmática: o significado racional (entendido como validade jurídica) de uma norma reside exclusivamente na sua implicação (concebível) sobre a conduta. A definição do "princípio do discurso", portanto, formula-se de modo pragmático.

Ao longo deste artigo, pretendemos argumentar que a filosofia do direito de Habermas foi também animada, em aspectos fundamentais, pelo espírito pragmatista norte-americano. A confirmação da influência do espírito pragmatista na teoria do discurso do direito e da democracia de Habermas possibilita compatibilizar a sua reflexão no campo do direito com a arquitetura maior que sustenta seu pensamento nos demais domínios por onde se aventurou: a epistemologia, a teoria social e a teoria política. Todavia, como sublinhamos, existem muitos pragmatismos, tanto na filosofia como no direito. Na verdade, o que parece estar implicado é a ambivalência semântica do termo pragmatismo em si, a qual extrapola discussões disciplinares e alcança em 
seu âmago o próprio significado deste conceito. Neste momento, cabe-nos somente salientar, ironicamente, a ubiquidade do termo - ora, como se sabe, o principal objetivo da Máxima de Peirce era tornar nossas ideias mais claras; formular um método seguro para a determinação de conceitos intelectuais, institutos e categorias.

Talvez seja o momento de indagarmos acerca da possibilidade de se vindicar a versão peirciana do pragmatismo clássico como pano de fundo para a filosofia do direito de Habermas. Nessa perspectiva, o direito seria encarado como o médium propício à concretização da "comunidade de investigadores" de Peirce. Certamente, a defesa de uma perspectiva filosófica realista no plano da validade normativa coloca o quadro teórico-filosófico dos dois autores em linha de continuidade e, ao mesmo tempo, em contraposição às propostas pragmatistas que hoje identificamos na epistemologia e no direito. Se Habermas é mesmo um intelectual animado pelo espírito pragmatista em todos os domínios de sua intervenção intelectual, tal espírito formou-se sob a influência da tradição clássica do pragmatismo norte-americano, cuja proposta nada tem a ver com a versão renovada ou renascida que domina no cenário filosófico contemporâneo. A identificação de Habermas com esta escola de pensamento pretendeu enquadrar o autor na linha da tradição clássica, em franca oposição ao neopragmatismo de Rorty e Posner, cujas teses dominam os discursos pragmatistas contemporâneos. Habermas, nesse quadro, poderia sim ser visto como um pragmatista, mas um pragmatista que é mais afeito ao estilo clássico desta escola de pensamento; como diria Haack, um pragmatista de estilo neoclássico.

\section{Referências}

APEL, Karl-Otto (1973). De Kant a Peirce: a transformação semiótica da lógica transcendental. In: . Transformação da filosofia II: o a priori da comunidade de comunicação. São Paulo: Loyola, 2000.

APEL, Karl-Otto (1998). Fundamentação normativa da "teoria crítica": recorrendo à eticidade do mundo da vida?: uma tentativa de orientação transcendental pragmática: com Habermas, contra Habermas. In: MOREIRA, Luiz (Org.). Com Habermas, contra Habermas: direito, discurso e democracia. São Paulo: Landy, 2004.

DE WAAL, Cornelis. Peirce revisitado: a virada normativa. In: Sobre pragmatismo. São Paulo: Loyola, 2007.

HAACK, Susan. Introduction: Pragmatism, Old and New. In: HAACK, Susan (Ed.). Pragmatism, Old and New: Selected Writings. Amherst: Prometheus Books, $2006 \mathrm{a}$. HAACK, Susan. Not Cynicism, but Synequism: Lessons from Classical Pragmatism. In: SHOOK, John R.; MARGOLIS, Joseph (Ed.). A Companion to Pragmatism. Cambridge: Blackwell Publishing, 2006b. 
HAACK, Susan. Reflections on Relativism. In: Moderate. Chicago: The University of Chicago Press, 1998. Manifesto of a Passionate HABERMAS, Jürgen (1981). The Paradigm Shift in Mead and Durkheim: From Purposive Activity to Communicative Action. In: . The Theory of

Communicative Action. Boston: Beacon Press, 1987. v. 2: Lifeworld and Systems: a Critique of Functionalist Reason.

HABERMAS, Jürgen (1989). Charles Sanders Peirce sobre comunicación. In: Textos e contextos. Barcelona: Ariel, 1996.

HABERMAS, Jürgen. Between Facts and Norms: a Discourse Theory of Law and Democracy. Cambridge: Cambridge University Press, 1996.

HABERMAS, Jürgen. Peirce's Logic of Inquiry: The Dilemma of a Scholastic Realism Restored by the Logic of Language. In: . Knowledge and Human Interest. Boston: Beacon Press, 1971.

HABERMAS, Jürgen. Richard Rorty's Pragmatic Turn. In: BRANDOM, R. (Ed.). Rorty and His Critics. Oxford: Blackwell Publishing, 2000.

LOVEJOY, Arthur Oncken. The Thirteen Pragmatisms. Baltimore: John Hopkins Press, 1963.

PEIRCE, Charles. The Collected Papers of Charles Sanders Peirce. Edited by Charles Hartshorne and Paul Weiss. Cambridge: The Belknap Press of Harvard University Press, 1974. v. 5-6. 